\title{
NGL-05-002-105 NAG9-4/6
}

Impact-Induced Devolatilization and Hydrogen Isotopic Fractionation of Serpentine:

Implications for Planetary Accretion

JoNnSontent

James A. Tyburczy

Department of Geology

Arizona State University

Tempe, AZ 85287

R.V. Krishnamurthy, Samuel Epstein

Division of Geological and Planetary Sciences

Califomia Institute of Technology

Pasadena, CA 91125

and

Thomas J. Ahrens

Seismological Laboratory

California Institute of Technology

Pasadena, CA 91125

(WASA-CR-182877) IMPACT-INDUCED

DEV OLATILIZ ATION AND HYDROGEN ISOTOPIC
FRACTIONATION OF SERPENTINE: IMPLICATICNS
FOR PLANETARY ACCRETION

Univ.) $36 \mathrm{p}$

fArizona state

$\begin{array}{lll}\text { CSCL } 070 & \text { G } 3 / 25 & \text { Unclas } \\ 0142316\end{array}$

N 88-22966

EPSL $\quad 4 / 88$ 


\begin{abstract}
Impact-induced devolatilization of porous serpentine was investigated using two independent experimental methods, the gas recovery method and the solid recovery method, each yielding nearly identical results. For shock pressures near incipient devolatilization $\left(P_{\text {initial }}=5.0 \mathrm{GPa}\right)$, the hydrogen isotopic composition of the evolved $\mathrm{H}_{2} \mathrm{O}$ is very close to that of the starting material. For shock pressures at which up to $12 \%$ impact-induced devolatilization occurs (up to $P_{\text {initial }}=7.7$ $\mathrm{GPa}$ ), the bulk evolved gas is significantly lower in deuterium than the starting material. There is also significant reduction of $\mathrm{H}_{2} \mathrm{O}$ to $\mathrm{H}_{2}$ in gases recovered at these higher shock pressures, probably caused by reaction of evolved $\mathrm{H}_{2} \mathrm{O}$ with the metal gas recovery fixture. Gaseous $\mathrm{H}_{2} \mathrm{O}-\mathrm{H}_{2}$ isotopic fractionation suggests high temperature (1100-1200 K) isotopic equilibrium between the gaseous species, indicating initiation of devolatilization at sites of greater than average energy deposition (shear bands). Bulk gas-residual solid isotopic fractionations indicate nonequilibrium, kinetic control of gas-solid isotopic ratios. Impact-induced hydrogen isotopic fractionation of hydrous silicates during accretion can strongly affect the long-term planetary isotopic ratios of planetary bodies, leaving the interiors enriched in deuterium. Depending on the model used for extrapolation of the isotopic fractionation to devolatilization fractions greater than those investigated experimentally, planetary interior enrichments of 4 to 30 per cent in $\mathrm{D} / \mathrm{H}$ relative to that of the incident material can result from this process.
\end{abstract}




\section{INTRODUCTION}

Impact-induced devolatilization of volatile-bearing rocks and minerals is an important process influencing planetary accretion, early atmosphere formation, and chemical weathering of planetary surfaces $[1,2,3,4,5]$. Previous experimental investigations of this process have focussed on the shock pressure (impact velocity) dependence of the extent of impact-induced devolatilization in hydrous minerals, carbonates, and meteorites $[6,7,8,9,10]$ and on the shock enhancement of chemical reactivity of silicates $[11,12]$. In this study, we perform a direct comparison of the two experimental techniques for measuring impact-induced devolatilization, namely, the gas-recovery and solid-recovery techniques. In addition, we have examined the hydrogen isotopic composition of the gaseous products of impact-induced devolatilization of serpentine.

Early experimental investigations of impact-induced devolatilization employed gas recovery techniques, in which the gas driven from a sample during impact was recovered directly and analyzed gravimetrically [6] or manometrically and isotopically [7]. The purpose of these early studies was to establish the existence of the impact-induced devolatilization process. Accordingly, shock pressures were investigated only up to the point of incipient devolatilization, the shock pressure at which the material just begins to release volatiles upon impact. Subsequent studies that more fully delineated the shock pressure dependence of the extent of impact-induced devolatilization utilized solid recovery methods, in which solid material was recovered after the impact and analyzed for its post-shock volatile content $[8,9,10]$. Differences in volatile content between unshocked material and recovered, shocked material were attributed to the impact process. A potential difficulty with the solid recovery method is the problem of the handling of the materials between the shock event and the volatile analysis. The shocked assemblies must be machined open to recover the sample, and given the extremely reactive nature of these materials, the question can be raised whether even brief exposure to the ambient atmosphere compromises the samples.

This study was performed 1) to directly compare impact-induced devolatilization results using 
gas recovery and solid recovery techniques, and 2) to examine the chemical and isotopic

composition of the gases evolved during impact into a hydrous sample. Direct comparison of solidand gas-recovery techniques has not been made previously, although the higher pressure solid recovery data are consistent with the incipient devolatilization pressures of the earlier gas-recovery work. In the only study to date of the isotopic composition of shock-evolved gases, $\mathrm{CO}_{2}$ evolved by shocking calcite just to the point of incipient devolatilization had the same $\mathrm{C}$ - and $\mathrm{O}$-isotopic composition as the starting material [7]. On the other hand, it has been suggested that vapor fractionation of impact-produced melt could provide an explanation for the relatively low $\delta^{18} \mathrm{O}$ ratios in tektites [13]. No previous examination of the isotopic composition of gases driven by impact from a hydrous mineral has been performed.

\section{EXPERIMENTAL}

The impact experiments were performed on a nearly pure magnesium end-member, polycrystalline lizardite serpentine collected near Globe, Arizona (Caltech Mineral Collection, Specimen Number 3221). The bulk chemical analysis is shown in Table 1 . The density of the mineral is $2.50 \pm 0.02 \mathrm{~g} / \mathrm{cm}^{3} ; \delta D_{\text {SMOW }}$ is -77 per mil.

Solid-recovery impact-induced devolatilization experiments were performed on the $20 \mathrm{~mm}$ powder gun at the California Institute of Technology using vented, stainless steel sample assemblies and thermogravimetric analysis of the recovered material as described previously $[6,10]$. Sample powders pressed to approximately 80 to $85 \%$ of the bulk mineral density were studied. Porous materials were studied because the high temperatures accompanying shock compression of porous materials lead to increased devolatilization at a given shock pressure relative • to nonporous materials. Thermogravimetric analysis (TGA) of shocked and unshocked samples was performed over the temperature range 300 to $1100^{\circ} \mathrm{C}$ using a Mettler Thermoanalyzer $2000 \mathrm{C}$. Sample size was approximately $20 \mathrm{mg}$. Analysis was performed in a nitrogen atmosphere. The extent of impact-induced devolatilization was determined by comparison of TGA analyses of 
shocked and unshocked material. Table 2 lists the results of the solid recovery experiments.

Gas-recovery experiments were performed using the assembly sketched in Figure 1. This assembly is a modification of that employed by Boslough et al. [7]. The sample powder was pressed into a wafer, inserted into the assembly, and held in place by the threaded containment plug. Sample densities were approximately 80 to $85 \%$ of the bulk mineral density. Sample dimensions were about $0.5 \mathrm{~mm}$ in diameter by $0.5 \mathrm{~mm}$ thick. Sample masses were between 14 and $21 \mathrm{mg}$. The impacted surface-to-sample distance was approximately $0.6 \mathrm{~cm}$. After loading the sample, the chamber was assembled, evacuated to less than $10 \mu \mathrm{m} \mathrm{Hg}$ pressure using a diffusion pump, and heated at $75^{\circ} \mathrm{C}$ overnight. Prior to the impact experiment, the assembly was again evacuated, the valve tightly closed, and the assembly mounted on the gun barrel. After the impact, the assembly was connected to a vacuum system, and the trapped gases were transferred through the valve section to the vacuum system for manometric and isotopic analysis. The integrity of the sample assembly was maintained for impact velocities up to $1.22 \mathrm{~km} / \mathrm{s}$. Impact velocities greater than $1.3 \mathrm{~km} / \mathrm{s}$ resulted in rupture of the chamber. A blank experiment was run in which no sample was placed into the assembly, and the recovered gases were analyzed in the same manner as the sample-bearing experiments. In general, in the gas recovery experiments the solid could not be recovered; it was spread as a fine dust over the interior of the assembly. In one shot, however, enough solid material was recovered to perform TGA (shot 867). The independent results for this shot are listed in Tables 2 and 3. For this shot, the agreement between the two techniques is excellent.

Manometric analysis of the recovered gases was performed using standard techniques [14]. The first separation was into noncondensible and condensible fractions at liquid nitrogen temperature. The noncondensible portion was further separated into a fraction that condensed onto molecular seive at liquid nitrogen temperature and the portion that did not condense. Subsequent mass spectrometric analysis of this 'doubly' noncondensible material established its identity as $\mathrm{H}_{2}$, and its $\mathrm{D} / \mathrm{H}$ ratio was determined. $\mathrm{CO}_{2}$ was released from the first condensible portion with an 
organic solvent-Dry Ice bath. The final $\mathrm{H}_{2} \mathrm{O}$ portion was reduced to $\mathrm{H}_{2}$ by passing it through uranium at $700^{\circ} \mathrm{C}$ and then analyzed mass spectrometrically. The results of the manometric and isotopic analyses for the blank- and sample-derived gases are listed in Table 3. Figure 2 illustrates the amounts of each gas fraction recovered for each of the gas-recovery experiments. The background levels of non-condensible gases, $\mathrm{H}_{2}$, and $\mathrm{H}_{2} \mathrm{O}$ recovered are significantly lower than amounts recovered from sample-containing shots, indicating that these recovered gases originate from the sample. Recovered $\mathrm{CO}_{2}$ is on the order of $1 \mu$ mole or less in all of the shots. The blank, impacted at $1.11 \mathrm{~km} / \mathrm{s}$, yielded $0.4 \mu$ moles of $\mathrm{H}_{2}$ and $1.0 \mu$ mole of $\mathrm{H}_{2} \mathrm{O}$, amounts insufficient for accurate mass spectrometric determination of $\mathrm{D} / \mathrm{H}$ ratios. These amounts were subtracted from the total $\mathrm{H}_{2}$ plus $\mathrm{H}_{2} \mathrm{O}$ recovered in determining the fraction of initial $\mathrm{H}_{2} \mathrm{O}$ volatilized during the impact.

Shock pressures were calculated using a one-dimensional impedance match solution [15]. We report both the initial shock pressure and the peak reverberated shock pressure in Tables 2 and 3. Equation of state parameters for stainless steel were taken from [16]; for serpentine we used initial (nonporous) density $\rho_{o}=2.50 \mathrm{~g} / \mathrm{cm}^{3}, C_{o}=5.30 \mathrm{~km} / \mathrm{s}$, and $\mathrm{s}=0.78$ [17], where shock velocity $U_{s}$ and particle velocity $u_{p}$ are related by $U_{s}=C_{o}+s u_{p}$. The Hugoniot of porous serpentine was calculated using the relation

$$
P_{H, p}=P_{H, d}\left\{1-\gamma\left(\left(\rho_{H} / \rho_{O}\right)-1\right] / 2\right\} /\left\{1-\gamma\left(\left(\rho_{H} / \rho_{\infty}\right)-1\right] / 2\right\}
$$

[18]. In equation (1) $\mathrm{P}_{\mathrm{H}, \mathrm{P}}$ is the Hugoniot pressure of the porous material, $\mathrm{P}_{\mathrm{H}, \mathrm{d}}$ is the Hugoniot pressure (at $\rho_{H}$ ) of the nonporous material, $\gamma$ is the Grüneisen parameter, $\rho_{H}$ is the Hugoniot density, $\rho_{0}$ is the initial density of the nonporous material, and $\rho_{\infty}$ is the initial porous material density. The Grüneisen parameter is calculated using $\gamma=\gamma_{0}\left(\rho_{0} / P_{H}\right)^{n}$ with $\gamma_{0}=1.0$ and $n=1.0$ [17]. Initial densities, impact velocities, and calculated initial and peak shock pressures are listed in Tables 2 and 3 . Experimentally determined errors in $\rho_{o}, \rho_{\infty}$, and projectile velocity $V_{p}$ were 
assumed to be independent and were propagated through the impedance match relations and equation (1) to yield uncertainties in initial and peak shock pressures [19].

\section{RESULTS AND DISCUSSION}

For the higher shock pressures studied, both $\mathrm{H}_{2}$ and $\mathrm{H}_{2} \mathrm{O}$ are found in the recovered gases and the $\mathrm{D} / \mathrm{H}$ ratios of both the $\mathrm{H}_{2}$ and $\mathrm{H}_{2} \mathrm{O}$ produced are significantly lower than that of the starting material (compare shot 867 with shots 911 and 915,Table 3). We postulate that the $\mathrm{H}_{2}$ in the recovered gas is a result of oxidation of iron metal in the experimental assembly according to the reaction

$$
\mathrm{Fe}+\mathrm{H}_{2} \mathrm{O}_{(\text {gas })}=\mathrm{FeO}+\mathrm{H}_{2} \text { (gas) }
$$

Under standard state thermodynamic conditions the products of this reaction are favored over reactants up to temperatures in excess of $1800 \mathrm{~K}$ [20], and for conditions in which $\mathrm{P}_{\mathrm{H} 2 \mathrm{O}}>\mathrm{P}_{\mathrm{H} 2}$, as is the case for the measured gas compositions of this study, this tendency will be enhanced. Reduction of $\mathrm{H}_{2} \mathrm{O}$ to $\mathrm{H}_{2}$ during pyrolysis of metal-containing carbonaceous chondrites has been observed [21]. In addition, measureable amounts of both $\mathrm{H}_{2}$ and $\mathrm{H}_{2} \mathrm{O}$ have been observed in mass spectrometric analyses of the spreading evaporation cloud of laser-shocked carbonaceous chondrites [22].

We compute the total $\mathrm{H}_{2} \mathrm{O}$ driven from serpentine by the shock as the sum of the $\mathrm{H}_{2} \mathrm{O}$ plus $\mathrm{H}_{2}$ collected, less the blank (shot 913). As indicated in Table 3, the actual $\mathrm{H}_{2}$ content of the noncondensible recovered gas fraction was not determined for each experimental shot. On the basis of the results for shots 911 and 915 , we assume that approximately $1 / 2$ of the total noncondensible gases recovered is $\mathrm{H}_{2}$. Accordingly, for shots 875 and 890 , the total $\mathrm{H}_{2}$ plus $\mathrm{H}_{2} \mathrm{O}$ recovered is calculated as the sum of the $\mathrm{H}_{2} \mathrm{O}$ recovered and $1 / 2$ of the noncondensible gases recovered. Figure 3 compares the impact-induced water loss for porous serpentine as a function of peak shock 
pressure determined in this study by the gas- and the solid-recovery methods. In the pressure region of overlap, the agreement is excellent. We conclude that the solid and gas recovery methods provide independent measures of the same phenomena and that previous impact-induced devolatilization results based on solid recovery methods are valid.

Figure 3 also shows the previous results for impact-induced devolatilization of nonporous (density $2.5 \mathrm{~g} / \mathrm{cm}^{3}$ ) serpentine [8]. The shock pressures for this previous work have been recalculated using the more recent serpentine equation of state data. The porous material shows significantly enhanced devolatilization over the nonporous material at the same shock pressure, consistent with expectations based on the higher shock temperature and shock entropy content of porous material [23]. The empirical best-fit polynomial curves for each data set have different curvatures. We interpret this difference as an artifact resulting from different shock-pressure distributions of the data in each set. That is, there are more low-pressure, low devolatilization fraction data for the porous material and more high-pressure, high devolatilization data for nonporous serpentine. The shock entropy model for impact-induced devolatilization indicates that the two curves should be of similar shape.

The hydrogen isotopic composition $\left(\delta \mathrm{D}=\left\{\left[(\mathrm{D} / \mathrm{H})_{\text {sample }} /(\mathrm{D} / \mathrm{H})_{\text {SMOW }}\right]-1\right\} \times 1000\right.$, where SMOW refers to Standard Mean Ocean Water) of the gaseous $\mathrm{H}_{2} \mathrm{O}$ recovered from shot 867 $\left(P_{\text {initial }}=5.0 \mathrm{GPa}\right)$ is nearly identical to that of the starting material, -72 compared to -77 per mil, respectively (Tables 1 and 3). However, for shots 911 and $915\left(P_{\text {initial }}=6.4\right.$ and $7.7 \mathrm{GPa}$, respectively) the recovered $\mathrm{H}_{2} \mathrm{O}$ has a significantly lower deuterium concentration than the starting serpentine, -93 and -98 per mil, respectively. The isotopic fractionation factor for hydrogen between the recovered $\mathrm{H}_{2} \mathrm{O}$ and $\mathrm{H}_{2}, \alpha_{\mathrm{H} 2} \mathrm{O}-\mathrm{H}_{2}=\left(1000+\delta \mathrm{D}_{\mathrm{H}_{2} \mathrm{O}}\right) /\left(1000+\delta \mathrm{D}_{\mathrm{H}_{2}}\right)=$ $(\mathrm{D} / \mathrm{H})_{\mathrm{H} 2} \mathrm{O} /(\mathrm{D} / \mathrm{H})_{\mathrm{H} 2}$, and the per mil difference, $\Delta_{\mathrm{H} 2} \mathrm{O}-\mathrm{H}_{2}=10^{3} \ln \alpha_{\mathrm{H} 2} \mathrm{O}-\mathrm{H}_{2}$, are listed in Table 4. For these two shots, the $\Delta_{\mathrm{H} 2} \mathrm{O}-\mathrm{H}_{2}$ values are 131 and 169 per mil, respectively. Hydrogen isotopic fractionation between gaseous $\mathrm{H}_{2} \mathrm{O}$ and $\mathrm{H}_{2}$ has been measured to $1000 \mathrm{~K}$ [24] and calculated theoretically [25]. For the experiments reported here, initial and peak shock temperatures 
were calculated using the procedures outlined by Tyburczy and Ahrens [23], the equation of state parameters for serpentine listed above, and these additional EOS parameters; zero-pressure adiabatic bulk modulus $\mathrm{K}_{\mathrm{OS}}=64 \mathrm{GPa}$, pressure derivative of the adiabatic bulk modulus $\mathrm{K}^{\prime}=2.7$, and specific heat capacity at constant volume $C_{v}=1.3 \mathrm{~J} /(\mathrm{g}-\mathrm{K})$ [17]. The calculated initial and peak shock temperatures lie between $600 \mathrm{~K}$ and $770 \mathrm{~K}$ (Table 4). Figure 4 is a plot of $\mathrm{H}_{2} \mathrm{O}-\mathrm{H}_{2}$ deuterium fractionation $\alpha_{\mathrm{H}_{2} \mathrm{O}-\mathrm{H}_{2}}$ versus temperature, showing both the equilibrium curve and the experimental results of this study. The values for the impact-derived gases lie at significantly lower temperatures than the equilibrium curve. If one assumes that the impact-produced $\mathrm{H}_{2} \mathrm{O}$ and $\mathrm{H}_{2}$ were in isotopic equilibrium, the measured values of $\alpha_{\mathrm{H}_{2} \mathrm{O}-\mathrm{H}_{2}}$ indicate equilibration temperatures of approximately $1100-1200 \mathrm{~K}$. This result suggests that shock-induced devolatilization is initiated at localized sites of thermal energy deposition, such as 'shear instability' regions $[26,27,28]$.

We calculate the bulk $\delta D$ of the released gases from the $\delta D$ and the molar amount of each gas species recovered. Then, using the initial $\delta \mathrm{D}$ of the serpentine and the fraction of $\mathrm{H}_{2} \mathrm{O}$ released during the shock, we obtain the bulk $\delta D$ of the residual solid and the fractionation factor $\alpha_{\text {gas-residue }}$ and the per mil difference $\Delta_{\text {gas-residue }}$ (Table 4). Values obtained for $\alpha_{\text {gas-residue }}$ are $1.005,0.941$, and 0.904 for shots 867,911 , and 915 , respectively. Values of $\alpha_{\mathrm{H} 2 \mathrm{O} \text {-residue }}$ calculated using the $\delta \mathrm{D}$ composition of the $\mathrm{H}_{2} \mathrm{O}$ recovered lie between 1.005 and 0.966 (Table 4). Figure 5 shows these results plotted versus shock temperature along with $\alpha_{\mathrm{H} 2 \mathrm{O} \text {-mineral for }}$ serpentine, muscovite, and thyolitic melt for comparison [29,30,31,32]. Electron microscopic images of shocked serpentine reveal vesicle-containing glassy regions, suggesting that the volatiles are evolved from shock-melted regions of the sample [8]. The trend of $\alpha_{\mathrm{H} 2 \mathrm{O} \text {-residue }}$ is inconsistent with the temperature trends of equilibrium $\mathrm{H}_{2} \mathrm{O}$-mineral or $\mathrm{H}_{2} \mathrm{O}$-melt $\mathrm{D}$-H

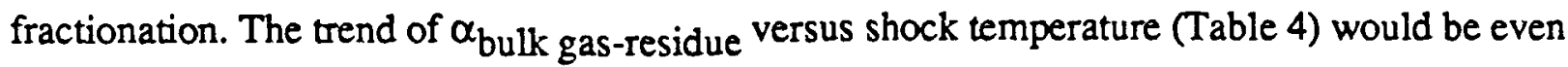
more discordant with the equilibrium curves. We conclude that the observed gas-residue isotopic fractionations are the result of kinetic processes occurring during the impact event and do not reflect equilibrium fractionation. 
Thus, for shock pressures $\left(\mathrm{P}_{\text {initial }}=5.0 \mathrm{GPa}\right)$ near the point of incipient devolatilization, there is little or no reduction of $\mathrm{H}_{2} \mathrm{O}$ to $\mathrm{H}_{2}$ in the shock-evolved gases, and the hydrogen isotopic composition of the gas is very close to that of the starting material. For higher shock pressures, at which more impact-induced devolatilization occurs $\left(P_{\text {initial }} \geq 6.4 \mathrm{GPa}\right)$, the bulk evolved gas is significantly lower in deuterium than the starting material and there is significant reduction of $\mathrm{H}_{2} \mathrm{O}$ to $\mathrm{H}_{2}$, probably caused by reaction of evolved $\mathrm{H}_{2} \mathrm{O}$ with the container. The lack of isotopic fractionation at lower shock pressures is consistent with the results of Boslough et al. [7] for calcite. They found only minor variations in $\delta^{13} \mathrm{C}$ and $\delta^{18} \mathrm{O}$ between the starting material and the $\mathrm{CO}_{2}$ evolved for calcite shocked to incipient devolatilization pressures.

The influence of impact-induced hydrogen isotopic fractionation of hydrous silicates during accretion on planetary isotopic compositions depends on the mass fraction of the planet accreted in an impact velocity regime in which partial devolatilization of incident and impacted material occurs. For very high impact velocities, complete devolatilization occurs and no isotopic fractionation would take place. In order to model the effects of impact-induced hydrogen isotopic fractionation on planetary accretion, information on the fractionation over the entire devolatilization interval is required. Because of the impact-velocity limitations of our gas-recovery chambers, the present results extend only to devolatilization fractions of $12 \%$. Figure 6 shows the experimental bulk gas-residual solid fractionation factor $\alpha_{\text {bulk gas-residue }}$ as a function of devolatilized fraction $\mathrm{X}_{D}$ results of this study along with model extrapolations to higher $\mathrm{X}_{\mathrm{D}}$. Lacking a firm basis for extrapolation, we examine three possible models. Model 1 is a simple linear extrapolation of the experimental results; $\alpha_{\text {bulk gas-residue reaches a minimum value of } 0.33 \text { at }} X_{D}=1.0$. In model 2 we assume that $\alpha_{\text {bulk gas-residue decreases linearly to } 12 \% \text { devolatilization, then remains constant }}$ at a value of 0.9 . In model 3 we assume a simple parabolic function through the data, reaching $\alpha_{\text {bulk gas-residue }}=1.0$ at $X_{D}=1.0$.

To model the effects of impact-induced hydrogen isotopic fractionation on planetary accretion, we assume a very simplified homogeneous accretion model. We assume that the incident material 
and the planetary surface both are composed of serpentine (equation of state discussed above), and that the growing planet maintains a constant density equal to its final average density throughout the growth period. Under these conditions the minimum impact velocity $\mathrm{V}_{\mathrm{p}}$ is a linear function of radius $r$

$$
V_{p}=r \cdot\left(8 \pi G \rho_{\text {avg }} / 3\right)^{1 / 2}
$$

where $G$ is the gravitational constant and $\rho_{a v g}$ is the (present-day) average density of the planet [10]. Figure 7 is a plot of impact-induced devolatilization as a function of fractional radius for the Earth, Venus, Mars, and the Moon, using the parameterized devolatilization versus initial shock pressure expression for nonporous serpentine (dashed curve in Figure 3). For the Earth and Venus, impact-induced devolatilization of incident planetesimals would commence when each planet reached about $12 \%$ of its final radius; complete devolatilization would occur by the time the growing planet reached about $30 \%$ of its final radius. For Mars, incipient and complete devolatilization would occur at about $28 \%$ and $70 \%$, respectively, of the final radius. For a planet of the Moon's size and density, impact induced devolatilization begins at $60 \%$ of final radius, and at its final size, incident material would be $60 \%$ devolatilized on impact. The results presented in Figure 7 differ slightly from previous calculations [10] because of updates in the serpentine equation of state parameters.

We also assume that the volatile materials not released on impact remain associated with the solid planet and are subsequently buried. The volatiles released on impact either remain in the planetary atmosphere or recondense on the planetary surface and are remobilized during subsequent impacts. These simplifying assumptions allow us to calculate the total surface volatile budget or cumulative fraction devolatilized for each of these planetary bodies (Figure 8). For the Earth and Venus, nearly $99 \%$ of the incident volatiles remain at the planetary surface at the end of accretion, for Mars $86 \%$ remain at the surface, and for the Moon, $27 \%$ remain at the surface. In each case, the remainder is retained in the planetary interior.

For a given impact, the D-H fractionation relative to the incident material is calculated as 
follows. Mass balance requires that

$$
(\mathrm{D} / \mathrm{H})_{\mathrm{i}}=\mathrm{X}_{\mathrm{D}} \cdot(\mathrm{D} / \mathrm{H})_{\mathrm{gas}}+\left(1-\mathrm{X}_{\mathrm{D}}\right) \cdot(\mathrm{D} / \mathrm{H})_{\text {solid }}
$$

where $(\mathrm{D} / \mathrm{H})_{\mathrm{i}}$ is the $\mathrm{D} / \mathrm{H}$ ratio of the incident material and $\mathrm{X}_{\mathrm{D}}$ is the fraction devolatilized. Substituting $(\mathrm{D} / \mathrm{H})_{\text {gas }}=\alpha_{\text {bulk gas-residue }} \cdot(\mathrm{D} / \mathrm{H})_{\text {solid }}$ and rearranging yields the solid-initial fractionation

$$
\alpha_{\text {solid-initial }}=(\mathrm{D} / \mathrm{H})_{\text {solid }} /(\mathrm{D} / \mathrm{H})_{\mathrm{i}}=1 /\left[1+\mathrm{X}_{\mathrm{D}} \cdot\left(\alpha_{\text {bulk gas-residue }}-1\right)\right]
$$

Figure 9 shows the bulk gas and solid fractionations for Mars as a function of planetary radius, illustrating the effects of the different $\alpha_{\text {bulk gas-residue }}-\mathrm{X}_{\mathrm{D}}$ models (Figure 6 ). The linear model, the most extreme of the models, yields a maximum $(\mathrm{D} / \mathrm{H})_{\text {solid }}$ nearly 3 times $(\mathrm{D} / \mathrm{H})_{\mathrm{i}}$ occurring at the radius at which complete devolatilization occurs. The minimum $\alpha_{\text {solid-initial }}$ is approximately 0.8 , occurring at $r / R=0.5$ when $X_{D}=0.62$. The more conservative models 2 and 3 reach

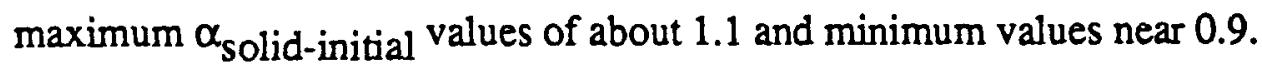

The cumulative effects of these fractionations are shown in Figure 10. Assuming that all the $\mathrm{H}_{2} \mathrm{O}$ devolatilized on impact accumulates in the atmosphere or on the surface, and that the remainder remains within the solid planet, cumulative bulk solid-incident fractionations at the end of accretion $(r / R=1.0)$ are $1.296,1.043$, and 1.061 for models 1,2 , and 3 , respectively. Cumulative bulk gas-incident fractionations are $0.96,0.99$, and 0.99 , respectively. Thus, depending on the exact nature of the gas-solid fractionation versus devolatilization relation, impact-induced hydrogen isotopic fractionation can lead to significant solid planet-atmosphere isotopic differences.

In Figures 11 and 12 we compare the effects of impact-induced isotopic fractionation using model 3 (the conservative, parabolic model) on the development of the Earth, Venus, Mars, and the • Moon. For the Earth, Venus, and Mars, each planet reaches sufficiently great size that complete devolatilization occurs during accretion (Figure 7). In each of these cases, the cumulative bulk solid $\mathrm{D} / \mathrm{H}$ ratio reaches the same final value of 1.06 , enriched in $\mathrm{D}$ relative to the incident material (Figure 12), because beyond the critical mass (radius) for complete devolatilization no additional volatile 
material is added to the planetary interior. The cumulative bulk atmospheric $\mathrm{D} / \mathrm{H}$ ratio varies continuously over accretion. For the Earth and Venus it asymptotically returns to that of the incident material. The atmospheric D/H ratio of Mars and a Moon-sized object would be $96 \%$ and $89 \%$, respectively, of the that of incident material.

Long term persistence of the impact-induced isotopic fractionation signature would further require isolation of the gas and solid isotopic reservoirs, either by rapid burial of the solid shocked material or by rapid planetary escape of the evolved gases. In the event of rapid removal (catastrophic or otherwise) of the earliest planetary atmosphere, the bulk planetary D/H ratio would be the cumulative solid $\mathrm{D} / \mathrm{H}$ ratio and would therefore be greater than that of the incident material.

The cumulative $\mathrm{D} / \mathrm{H}$ fractionations resulting from isotopic fractionation upon impact-induced devolatilization during accretion are not sufficient to explain the observed $\sim 6-$ and $\sim 10$-fold enrichments in the D/H ratios of the atmospheres of Mars and Venus relative to the Earth [33,34]. However, this previously unrecognized process can cause different reservoirs within an accreting planet to have $\mathrm{D} / \mathrm{H}$ ratios significantly different than those of the material from which the planet accumulated. The existence of these distinct reservoirs at the earliest stages of accretion will strongly influence the isotopic evolution of the body.

Note that the experiments reported here and the above discussion deal with fractionation of hydrogen from hydrous silicates. Hydrous silicates in meteorites have $\delta \mathrm{D}$ values around -100 per mil. An extremely wide range of $\delta \mathrm{D}$ values $(-500$ to $+10,000$ per mil) is found for the acid-insoluble organic material of chondritic meteorites [21,35]. The shock behavior of these materials is not known, but their occurrence in accreting materials would significantly affect $\mathrm{D} / \mathrm{H}$ ratios in a growing planet.

\section{CONCLUSIONS}

Two independent methods for investigating impact-induced devolatilization, the gas recovery method and the solid recovery method, yield nearly identical results for porous serpentine. For 
impacts into porous serpentine near the point of incipient devolatilization $\left(P_{\text {initial }}=5.0 \mathrm{GPa}\right)$, the evolved hydrogen-containing gases consist nearly entirely of $\mathrm{H}_{2} \mathrm{O}$ with a hydrogen isotopic composition very close to that of the starting material. For shock pressures at which up to $12 \%$ impact-induced devolatilization occurs $\left(P_{\text {initial }}=67.7 \mathrm{GPa}\right)$, the bulk evolved gas is significantly lower in deuterium than the starting material and there is significant reduction of $\mathrm{H}_{2} \mathrm{O}$ to $\mathrm{H}_{2}$, probably caused by reaction of evolved $\mathrm{H}_{2} \mathrm{O}$ with the container. Gaseous $\mathrm{H}_{2} \mathrm{O}-\mathrm{H}_{2}$ isotopic fractionations suggest high temperature (ca. 1100-1200K) isotopic equilibrium between the gaseous species, but bulk gas-residual solid fractionations indicate nonequilibrium, kinetic control of gas-solid isotopic fractionation. Impact-induced hydrogen isotopic fractionation of hydrous silicates during accretion can affect the long-term planetary $\mathrm{D} / \mathrm{H}$ ratios of smaller planetary bodies. $\mathrm{D} / \mathrm{H}$ ratios of planetary interiors may be enriched by factors of 5 to 30 per cent over that of the incident material, depending on the exact nature of the isotopic fractionation-impact devolatilization relation.

\section{ACKNOWLEDGEMENTS}

We thank Professor George Rossman for the use of his laboratory facilities. E. Gelle, M. Long, and C. Manning provided expert experimental assistance. Supported under NASA grants NGL-05-002-105 and NAG9-46. Caltech Division of Geological and Planetary Sciences contribution \#4516. 


\section{REFERENCES}

1 Arrhenius, G., B. R. De, and H. Alfven, Origin of the ocean. In The Sea (E. D. Goldberg, editor), pp.839-861, Wiley, New York, 1974.

2 Benlow, A., and A. J. Meadows, The formation of the atmospheres of the terrestrial planets by impact, Astrophys. Space Sci., 46, 293-300, 1977.

3 Jakosky, B. M., and T. J. Ahrens, The history of an atmosphere of impact origin, Proc. 101h Lunar Sci. Conf., 2727-2739, 1979.

4 Lange, M. A., and T. J. Ahrens, The evolution of an impact-generated atmosphere, Icarus, 51, 96-120, 1982.

$5 \mathrm{Abe}, \mathrm{Y}$., and T. Matsui, The formation of an impact-generated $\mathrm{H}_{2} \mathrm{O}$ atmosphere and its implications for the early thermal history of the Earth, Proc. 15th Lunar Sci. Conf., Part 2, J. Geophys. Res., 90, C545-C559, 1985.

6 Boslough, M. B., R. J. Weldon, and T. J. Ahrens, Impact-induced water loss from serpentine, nontronite, and kernite, Proc. 11th Lunar Sci. Conf., 2145-2158, 1980.

7 Boslough, M. B., T. J. Ahrens, J. Vizgirda, R. H. Becker, and S. Epstein, Shock-induced devolatilization of calcite, Earth Planet. Sci. Lett., 61, 166-170, 1982.

8 Lange, M. A., P. Lambert, and T. J. Ahrens, Shock effects on hydrous minerals and implications for carbonaceous meteorites, Geochim. Cosmochim. Acta, 49, 1715-1726, 1985.

9 Lange, M. A., and T. J. Ahrens, Shock-induced $\mathrm{CO}_{2}$ loss from $\mathrm{CaCO}_{3}$ : Implications for early planetary atmospheres, Earth Planet. Sci.Lett, 77, 409-418, 1986.

10 Tyburczy, J. A., B. Frisch, and T. J. Ahrens, Shock-induced volatile loss from a carbonaceous chondrite: Implications for planetary accretion, Earth Planet. Sci. Lett., 80, 201-207, 1986.

11 Boslough, M. B., and R. T. Cygan, Shock-enhanced dissolution of silicate minerals and chemical weathering on planetary surfaces, Proc. 18th Lunar Sci. Conf., G. Ryder, editor, 
pp.443-453, Cambridge University Press, 1988.

12 Tyburczy, J. A., and T. J. Ahrens, Dehydration kinetics of shocked serpentine, Proc. 18th Lunar Sci. Conf., edited by G. Ryder, pp. 435-441, Cambridge University Press, 1987.

13 Taylor, H.P., Jr., and S. Epstein, Correlations between $\mathrm{O}^{18} / \mathrm{O}^{16}$ ratios and chemical compositions of tektites, J. Geophys. Res.,74, 6834-6844, 1969.

14 Epstein, S., and H. P. Taylor, Jr., Investigation of the carbon, hydrogen, oxygen, and silicon isotope and concentration relationships on the grain surface of a variety of lunar soils and in Apolla 15 and 16 core samples, Proc. 6th Lunar Sci. Conf., 1771-1798, 1975.

15 Rice, M. H., R. G. McQueen, and J. M. Walsh, Compression of solids by strong shock waves, Solid State Phys., 6, 1-63, 1958.

16 Marsh, S. P. , ed., LASL Shock Hugonior Data, University of Califomia Press, Berkeley. 327 pp., 1980.

17 Tyburczy, J. A., and T. J. Ahrens, Shock wave equation of state of serpentine to $120 \mathrm{GPa}$, EOS, Trans. AGU,67, 1241, 1986.

18 Ahrens, T. J., and J. D. O'KeefeShock melting and vaporization of lunar rocks and minerals, Moon, 4, 214-249, 1972.

19 Bevington, P.R., Data Reduction and Error Analysis for the Physical Sciences, McGraw-Hill, New York, 336 pp, 1969.

20 Robie, R. A., B. S. Hemingway, and J. R. Fisher,Thermodynamic Properties of Minerals and Related Substances at $298.15 \mathrm{~K}$ and $1 \mathrm{Bar}\left(10^{5}\right.$ Pascals) Pressure and at Higher Temperatures, Geological Survey Bulletin 1452, U. S. Geological Survey, Washington, 456 pp., 1978.

21 Robert, F., and S. Epstein, The concentration and isotopic composition of hydrogen, carbon and nitrogen in carbonaceous meteorites, Geochim. et Cosmochim. Acta, 46, 81-95, 1982.

22 Geriasimov, M.V., B. L. Satovsky, and 1.M. Mukhin, Mass-spectrometrical analyses of gases originated during impulsive evaporation of meteorites and terrestrial rocks, Lunar Planet. Sci. 
XVIII, 3.22-323, 1987.

23 Tyburczy, J. A., and T. J. Ahrens,Dynamic compression and volatile release of carbonates, J. Geophys. Res., 91, 4730-4744, 1986.

24 Cerrai, E., C. Marchetti, R. Renzoni, M. Silvestri, and S. Villani, A thermal method for concentrating heavy water, Chem. Eng. Prog. Symp.Ser., 50(11), 271-280, 1954.

25 Richet, P., Y. Bottinga, and M. Javoy, A review of hydrogen, carbon, nitrogen, oxygen, sulphur, and chlorine stable isotope fractionation among gaseous molecules, Ann. Rev. Earth Planet. Sci., 5, 65-110, 1977.

26 Grady, D. E., Shock deformation of brittle solids, J. Geophys. Res., 85, 913-924, 1980.

27 Horie, Y., Thermodynamics of dislocations and shock compression of solids, Phys. Rev. B, 21, 5549-5557, 1980.

28 Kondo, K., and T. J. Ahrens, Heterogeneous shock-induced thermal radiation in minerals, Phys. Chem. Miner., 9, 173-181, 1983.

29 O'Neil, J. R., Theoretical and experimental aspects of isotopic fractionation. In Stable Isotopes in High Temperature Geological Processes, Reviews in Mineralogy, vol. 16., (J. W. Valley, H. P. Taylor, Jr., and J. R. O'Neil, editors); pp. 1-40, Mineralogical Society of America, Washington, 1986.

30 Taylor, B.E., Magmatic volatiles: Isotopic variation of C, H, and S. In Stable Isotopes in High Temperature Geological Processes, Reviews in Mineralogy, vol. 16., (J. W. Valley, H. P. Taylor, Jr., and J. R. ONeil, editors), pp. 185-226, Mineralogical Society of America, Washington, 1986.

$31 \mathrm{Liu}, \mathrm{K} . \mathrm{K}$. , and S. Epstein, The hydrogen isotope fractionation between kaolinite and water, Isotope Geoscience, 2, 335-350, 1984.

32 Sakai, $H$., and $M$. Tsutsumi, $D / H$ fractionation factors between serpentine and water at $100^{\circ}$ to $500^{\circ} \mathrm{C}$ and 2000 bar water pressure, and the D/H ratios of natural serpentines, Earth Planet. 
Sci. Lett., 40, 231-242, 1978.

33 Owen, T., B. L. Lutz, C. de Bergh, and J.-P. Maillard, Detection of HDO in the atmosphere of Mars: Its abundance and the value of D/H, Bull. Amer. Astron. Soc., 19, 817-818, 1987.

34 Kaye, J. A., Mechanisms and observations for isotope fractionation of molecular species in planetary atmospheres,Rev. Geophysics, 25, 1609-1658, 1987.

35 Yang, J., and S. Epstein, Interstellar organic matter in meteorites, Geochim. et Cosmochim. Acta, 47, 2199-2216, 1983. 
Table 1. Chemical composition of Giobe Arizona lizandite

$\begin{array}{lc}\mathrm{SiO}_{2} & 4228 \mathrm{wt} \% \\ \mathrm{TiO}_{2} & 0.04 \\ \mathrm{Al}_{2} \mathrm{O}_{3} & 0.42 \\ \mathrm{CaO} & 0.03 \\ \mathrm{MgO} & 41.94 \\ \mathrm{FeO} & 0.36 \\ \mathrm{MnO} & 0.08 \\ \mathrm{~K}_{2} \mathrm{O} & 0.02 \\ \mathrm{Na}_{2} \mathrm{O} & 0.01 \\ \mathrm{H}_{2} \mathrm{O} & \frac{12.7}{07.83}\end{array}$

$\mathrm{H}_{2} \mathrm{O}$ analysis by TGA. All other oxides analysed ty electrom minusyprobe. $\delta D_{\text {SMOW }}=-77$ per mill. 
Table 2. Solid Recovery Data

\begin{tabular}{cccccc} 
Shot Number Initial Sample & $\begin{array}{c}\text { Projectile } \\
\text { Density }\end{array}$ & $\begin{array}{c}\text { Initial Shock } \\
\text { Pressure }\end{array}$ & $\begin{array}{c}\text { Peak Shock } \\
\text { Pressure }\end{array}$ & $\begin{array}{c}\text { Impact-induced } \\
\text { H2O Loss }\end{array}$ \\
\hline $8 / \mathrm{cm} 3$ & $\mathrm{~km} / \mathrm{s}$ & $\mathrm{GPa}$ & $\mathrm{GPa}$ & $\%$ \\
87 & 2.09 & 0.85 & 5.0 & 17.5 & 3.9 \\
& \pm 0.04 & \pm 0.01 & \pm 1.4 & \pm 0.2 & \\
873 & 2.05 & 1.27 & 8.7 & 27.7 & 10.6 \\
& \pm 0.04 & \pm 0.01 & \pm 1.8 & \pm 0.3 & \\
870 & 2.03 & 1.60 & 11.9 & 36.4 & 38.3 \\
& \pm 0.04 & \pm 0.10 & \pm 4.8 & \pm 2.7 & \\
869 & 2.05 & 1.86 & 15.1 & 43.8 & 89.0 \\
& \pm 0.04 & \pm 0.01 & \pm 2.3 & \pm 0.3 &
\end{tabular}




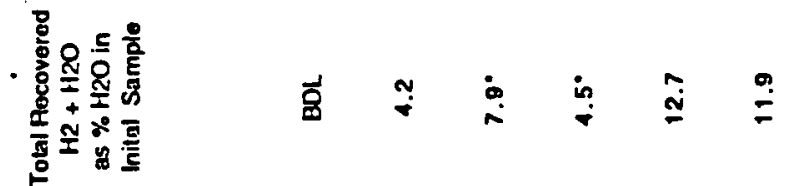

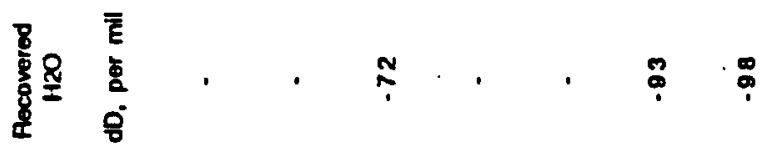

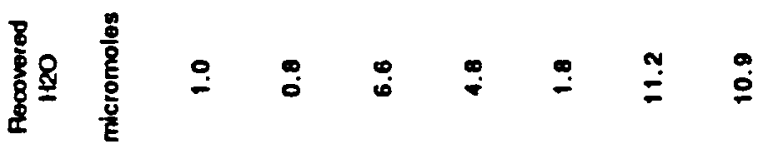

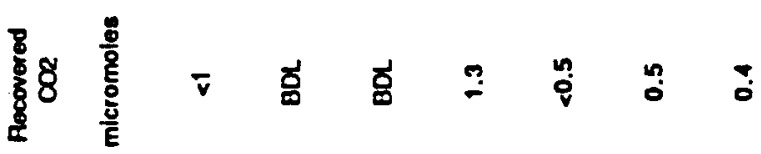

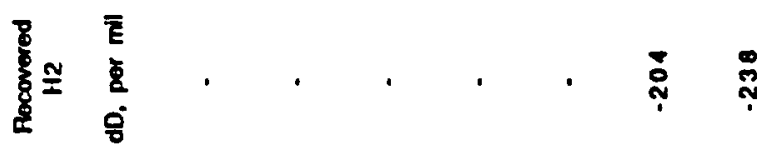

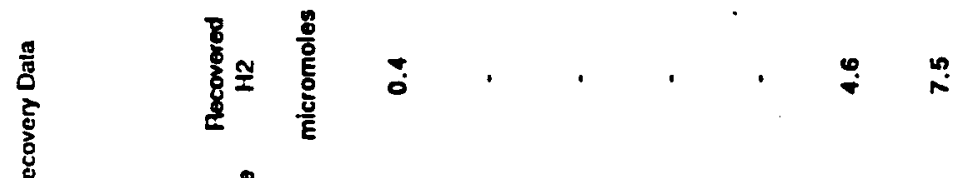

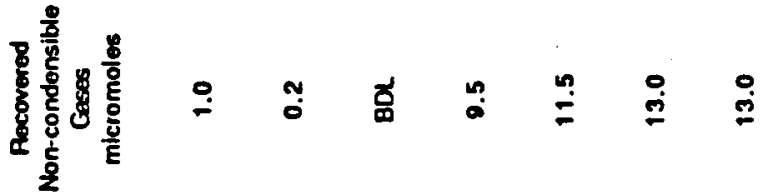

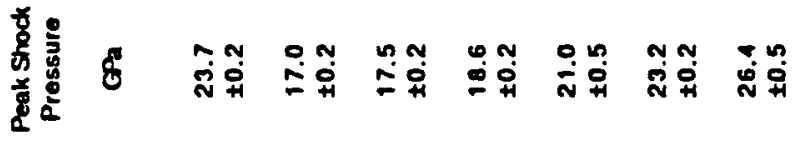

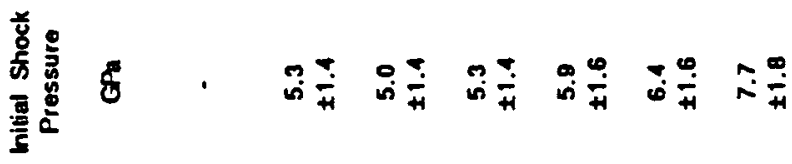

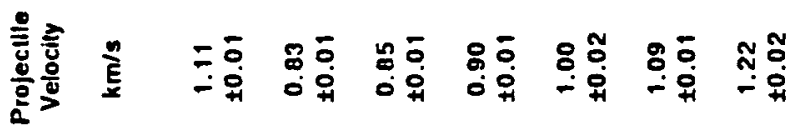

$$
\begin{aligned}
& \text { 要 } \\
& \text { 产 }
\end{aligned}
$$

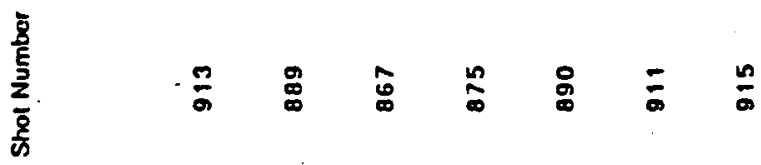

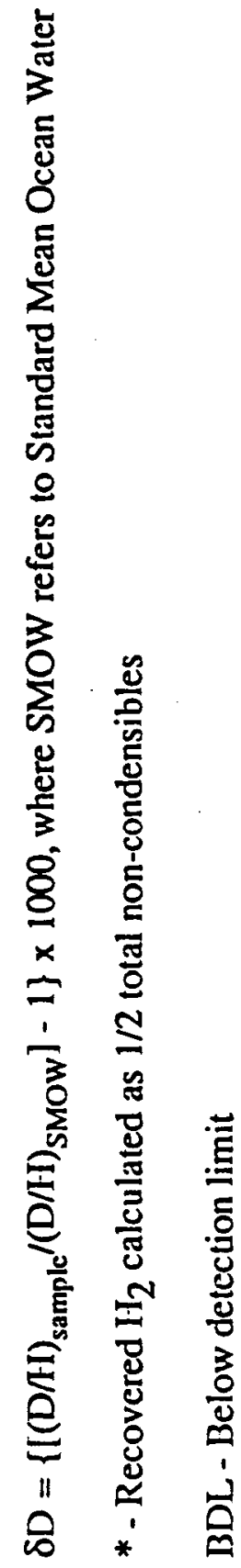


Table 4. Derived isoptopic parameters

Shot 867

$\alpha_{\mathrm{H} 2 \mathrm{O}-\mathrm{H} 2}$

$\Delta_{\mathrm{H} 2 \mathrm{O}-\mathrm{H}_{2}}$, per mil

$\mathrm{T}_{\text {init }}, \mathrm{K}$

$\mathrm{T}_{\text {peak }}, \mathrm{K}$

$\alpha_{\mathrm{H} 2 \mathrm{O}-\text { residual solid }}$

$\Delta_{\text {H2O-residual solid, }}$ per mil

$\delta \mathrm{D}_{\text {SMOW }}$, Bulk gas, per mil

$\delta \mathrm{D}_{\text {SMOW }}$, Residual solids, per mil

$\alpha_{\text {bulk gas-residual solid }}$

$\Delta_{\text {bulk gas-residual solid, }}$ per mil
1.005

Shot $911 \quad$ Shot 915

1.140

1.184

169

640

770

1.005

5

$-72$

$-125$

$-70$

.66

0.941

0.904

5

$-61$

$-101$ 


\section{FIGURE CAPTIONS}

Figure 1. Schematic diagram of the gas recovery assembly. Valve, Be-Cu alloy; all other parts, stainless steel 304.

Figure 2. Bulk chemical composition of recovered gases evolved from serpentine on impact. Shot 913 was an empty, background experiment impacted at $1.11 \mathrm{~km} / \mathrm{s}$. Other shots listed in order of increasing impact velocity.

Figure 3. Impact-induced water loss as a function of initial shock pressure for $20 \%$ porous serpentine (this study) and nonporous serpentine [8]. Filled squares, solid recovery method, porous serpentine (Table 2); open squares, gas recovery method, porous serpentine (Table 3); crosses, solid recovery method, nonporous serpentine. Solid line, empirical fit to data for porous serpentine; dashed line, empirical fit to data for noporous serpentine.

Figure 4. $\mathrm{H}_{2} \mathrm{O}-\mathrm{H}_{2} \mathrm{D} / \mathrm{H}$ fractionation factor versus temperature. Curve is theoretical result of [25]. Data are results for shots 911 and 915 plotted against calculated shock temperature (see text ).

Figure 5. $\mathrm{H}_{2} \mathrm{O}$-residual solid deuterium fractionation versus shock temperature (Table 4), open squares. Solid curves, $\mathrm{H}_{2} \mathrm{O}$-mineral deeuterium fractionation $[29,30,31,32]$.

Figure 6. Impact-induced bulk gas-residual solid fractionation $\alpha_{\text {bulk gas-residue }}$ as a function of devolatilization fraction $\mathrm{X}_{\mathrm{D}}$. Curves are assumed models for extrapolation (see text).

Figure 7. Impact-induced devolatilization of nonporous serpentine as a function of fractional planetary radius.

Figure 8. Cumulative impact-induced devolatilization of nonporous serpentine as a function of fractional planetary radius.

Figure 9. Impact-induced $\mathrm{D} / \mathrm{H}$ fractionation during accretion for Mars. Numbers refer to models of Figure 6.

Figure 10. Cumulative impact-induced $\mathrm{D} / \mathrm{H}$ fractionation during accretion for Mars. Numbers refer to models of Figure 6.

Figure 11. Impact-induced $\mathrm{D} / \mathrm{H}$ fractionation during accretion for Earth, Mars, Venus, and the Moon, using model 3 for bulk gas-residual solid D/H fractionation (Figure 6). 
Figure 12. Cumulative impact-induced D/H fractionation during accretion for Earth, Mars, Venus, and the Moon, using model 3 for bulk gas-residual solid D/H fractionation (Figure 6). 


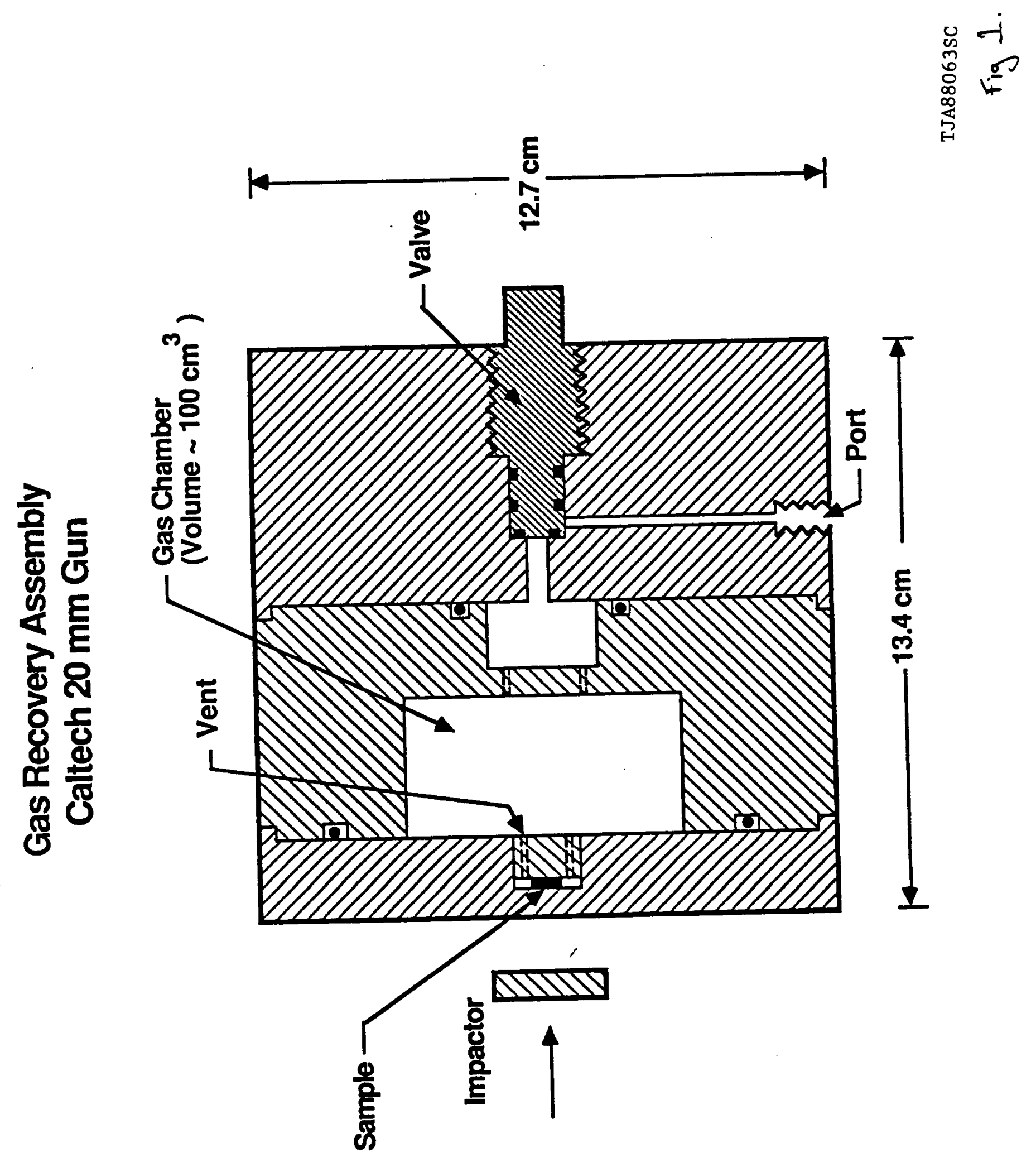




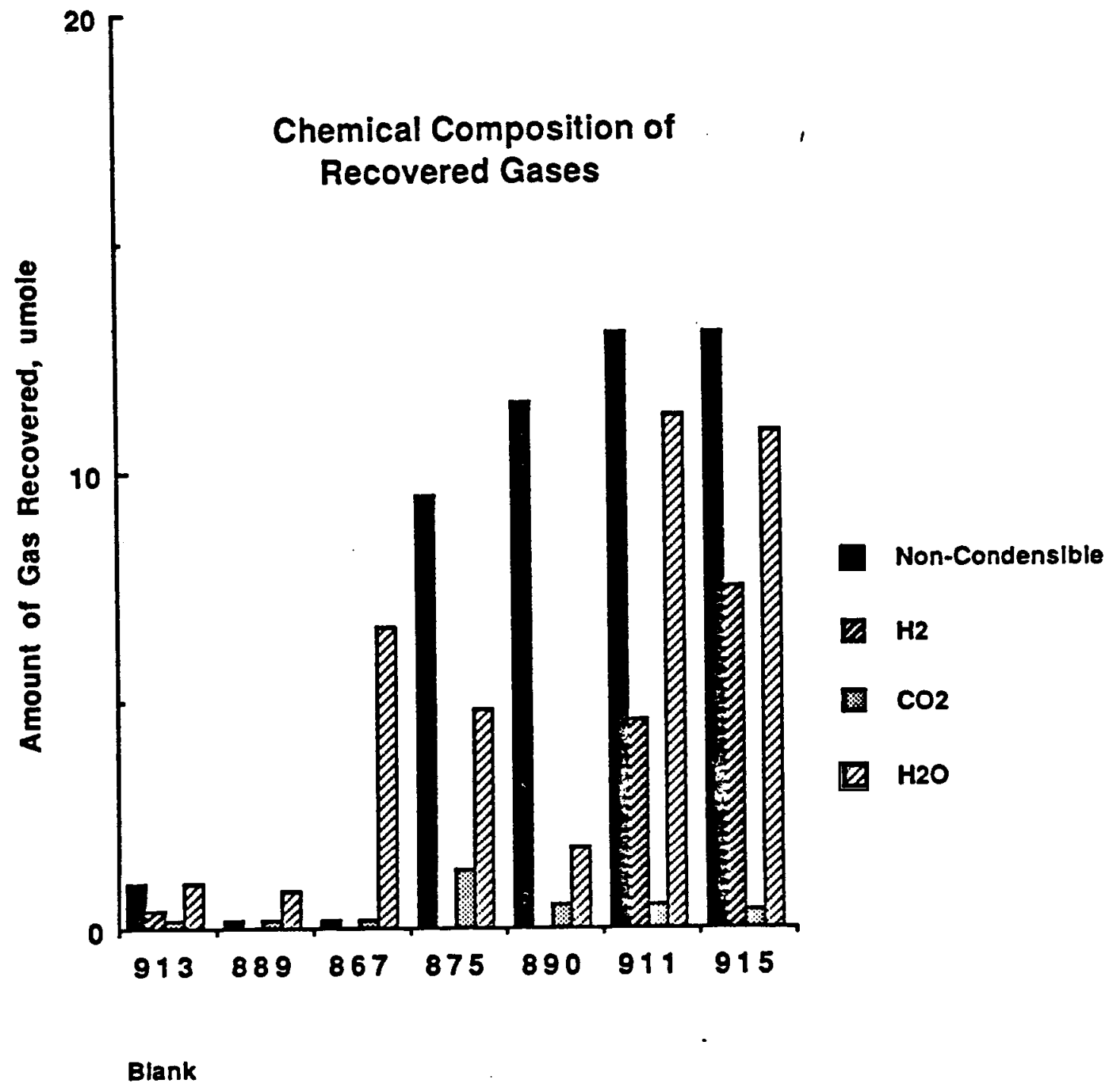

Shot Number

Figure?. 


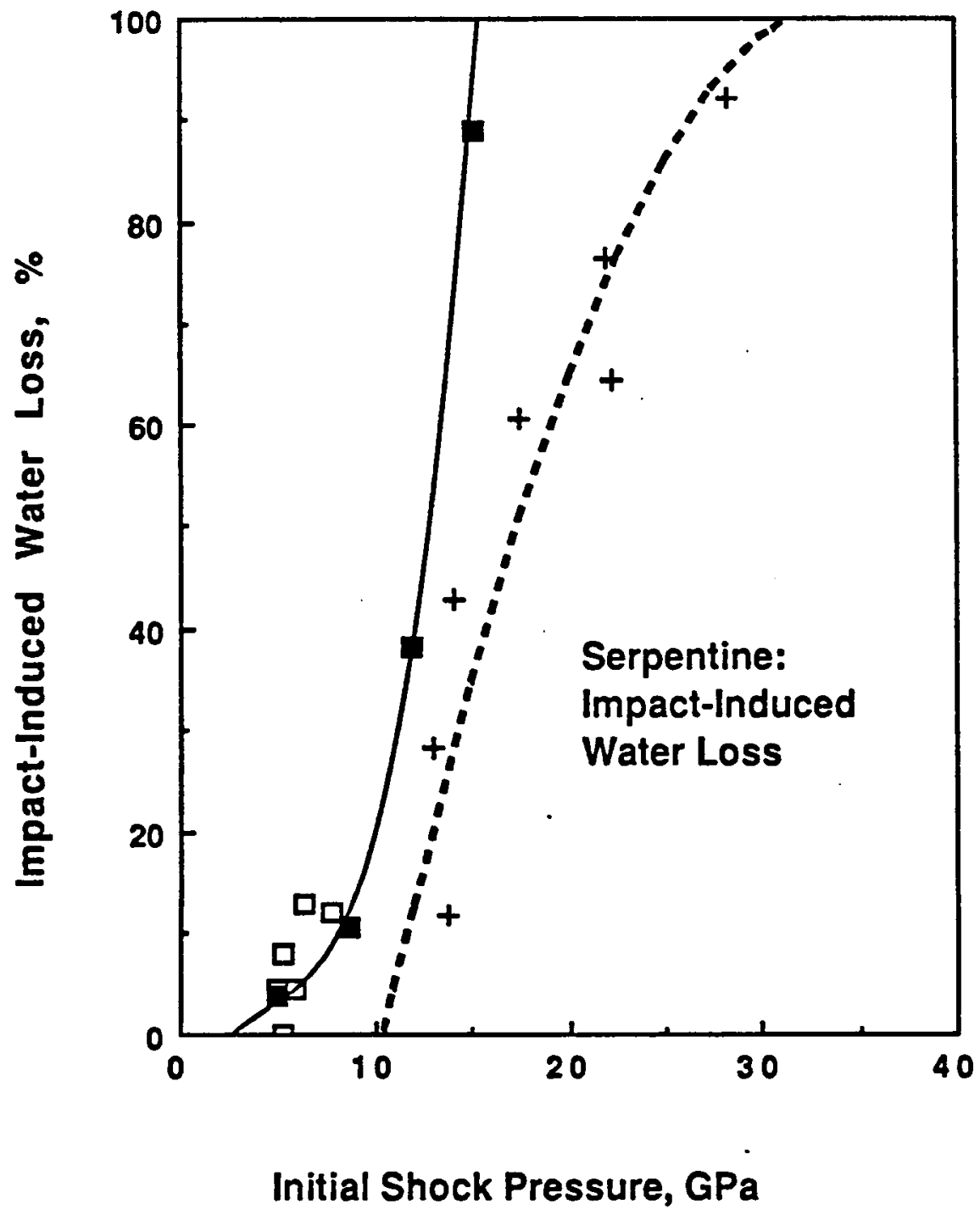

Figure 3 


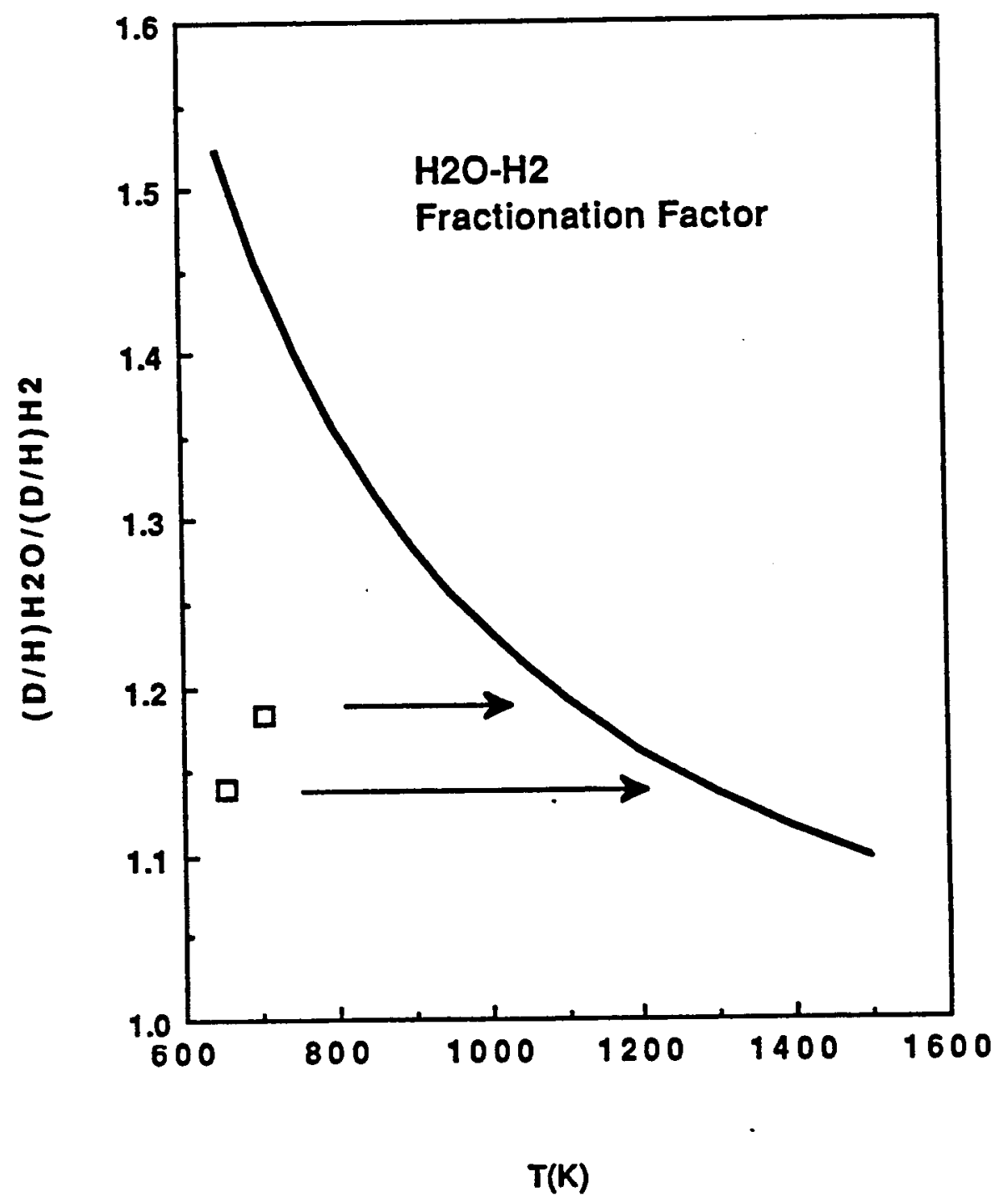

Figure 4 


\section{H2O-Solid Fractionation Factors}

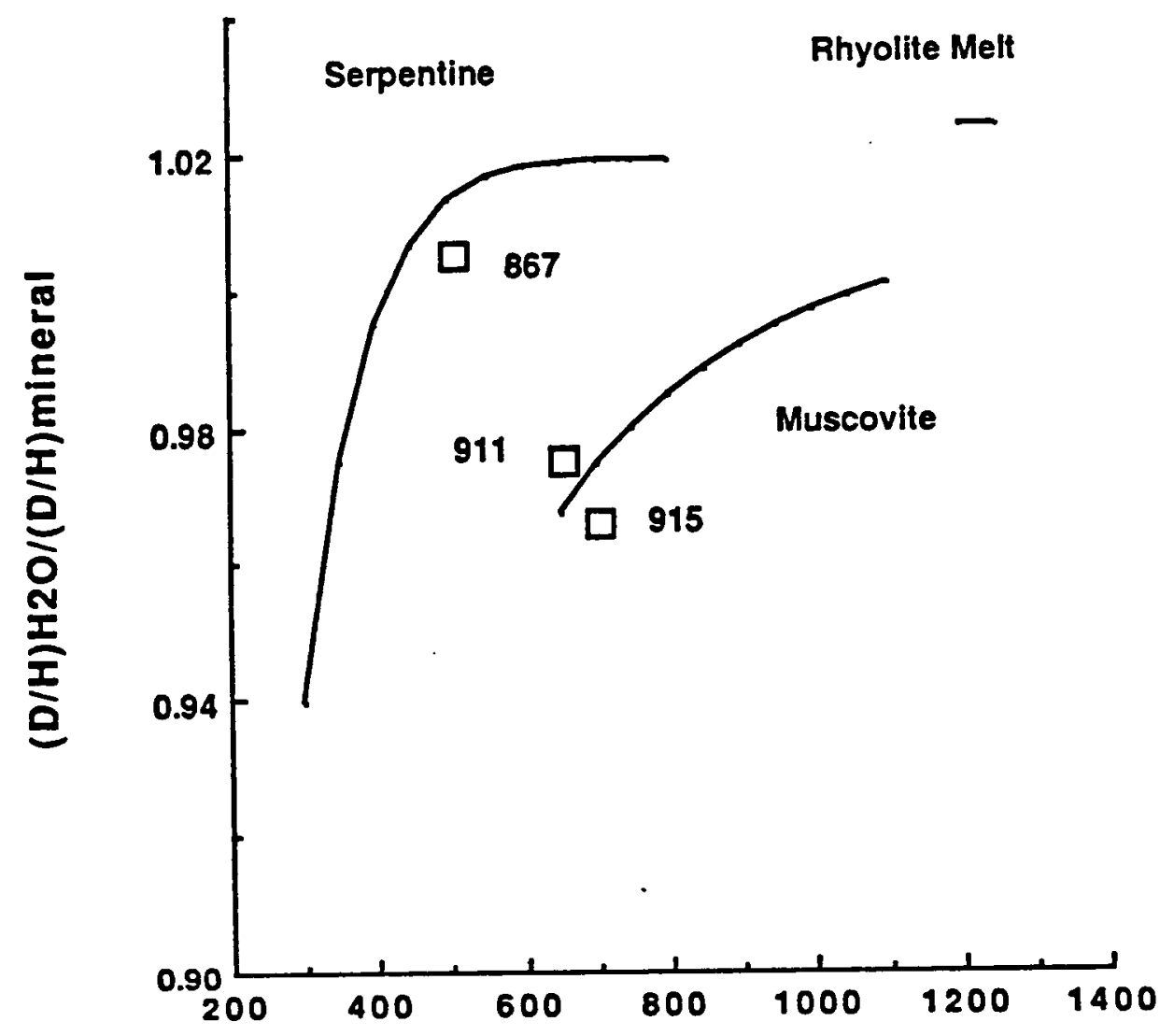

$T(K)$

Figure 5 
Bulk Gas-Residual Solid

Fractionation Factor:

Data and Models

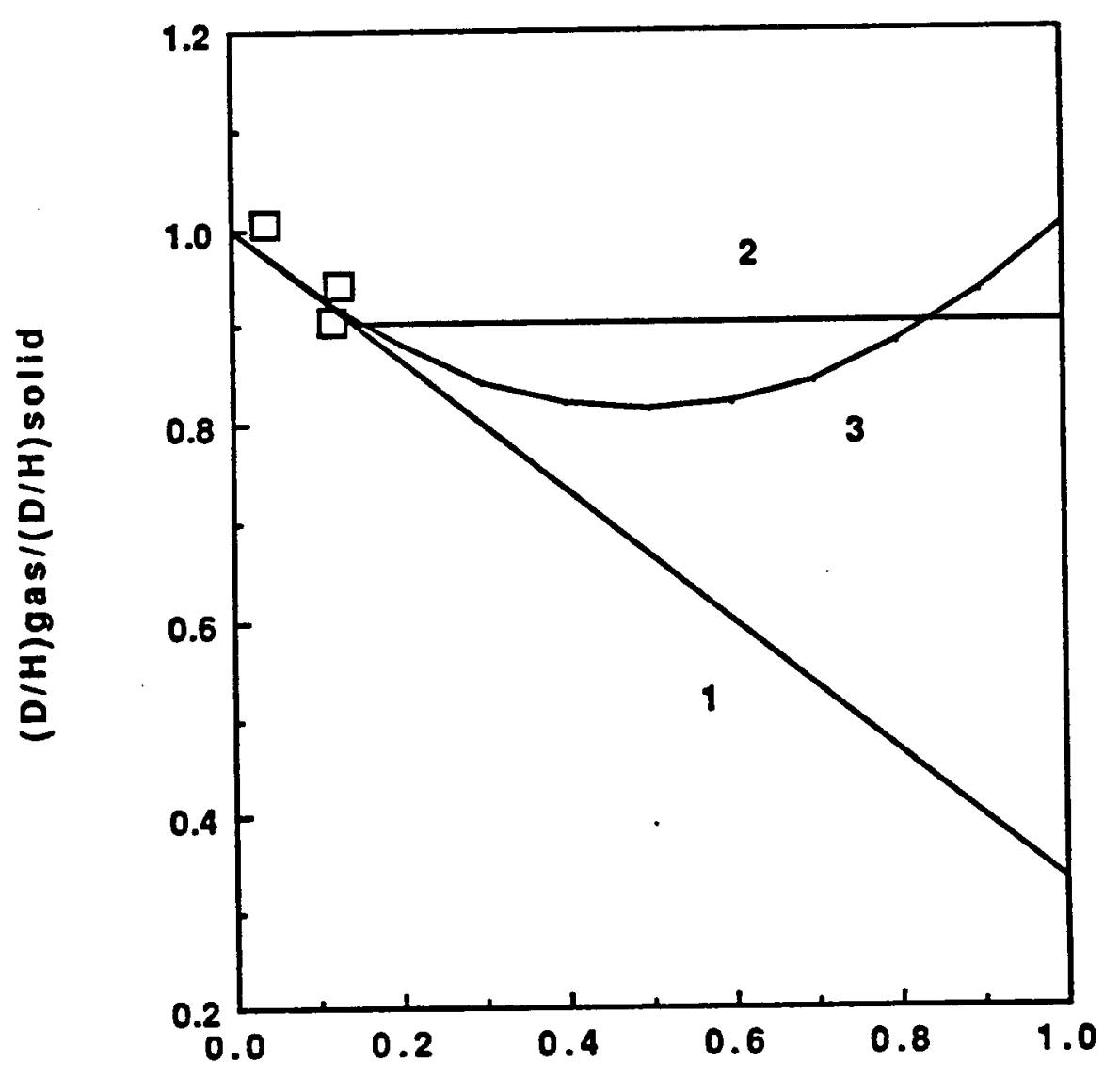

Fraction Devolatilized 
Impact-Induced Devolatilization During Accretion

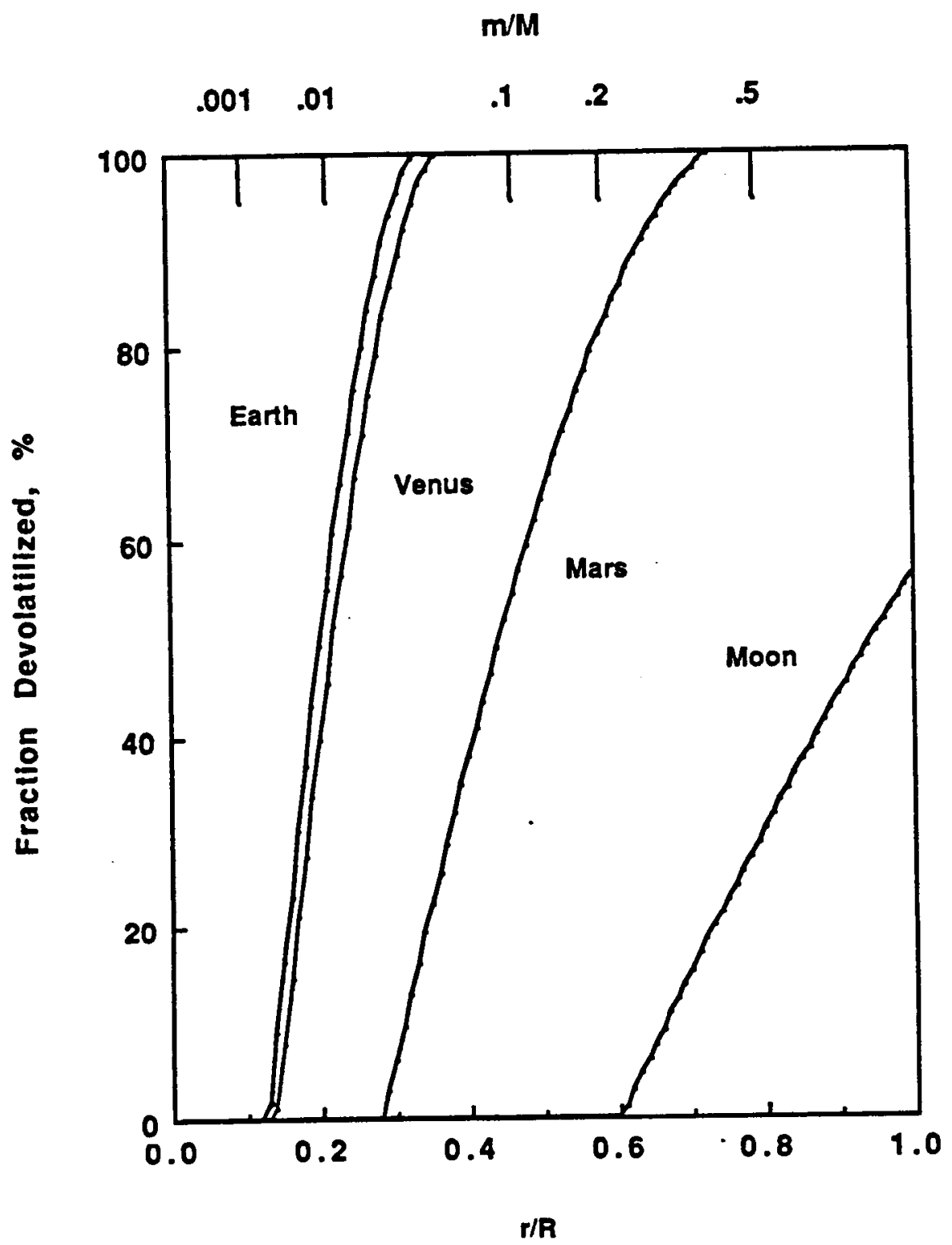

Fiqure 7 
Cumulative Impact-Induced

Devolatilization During Accretion

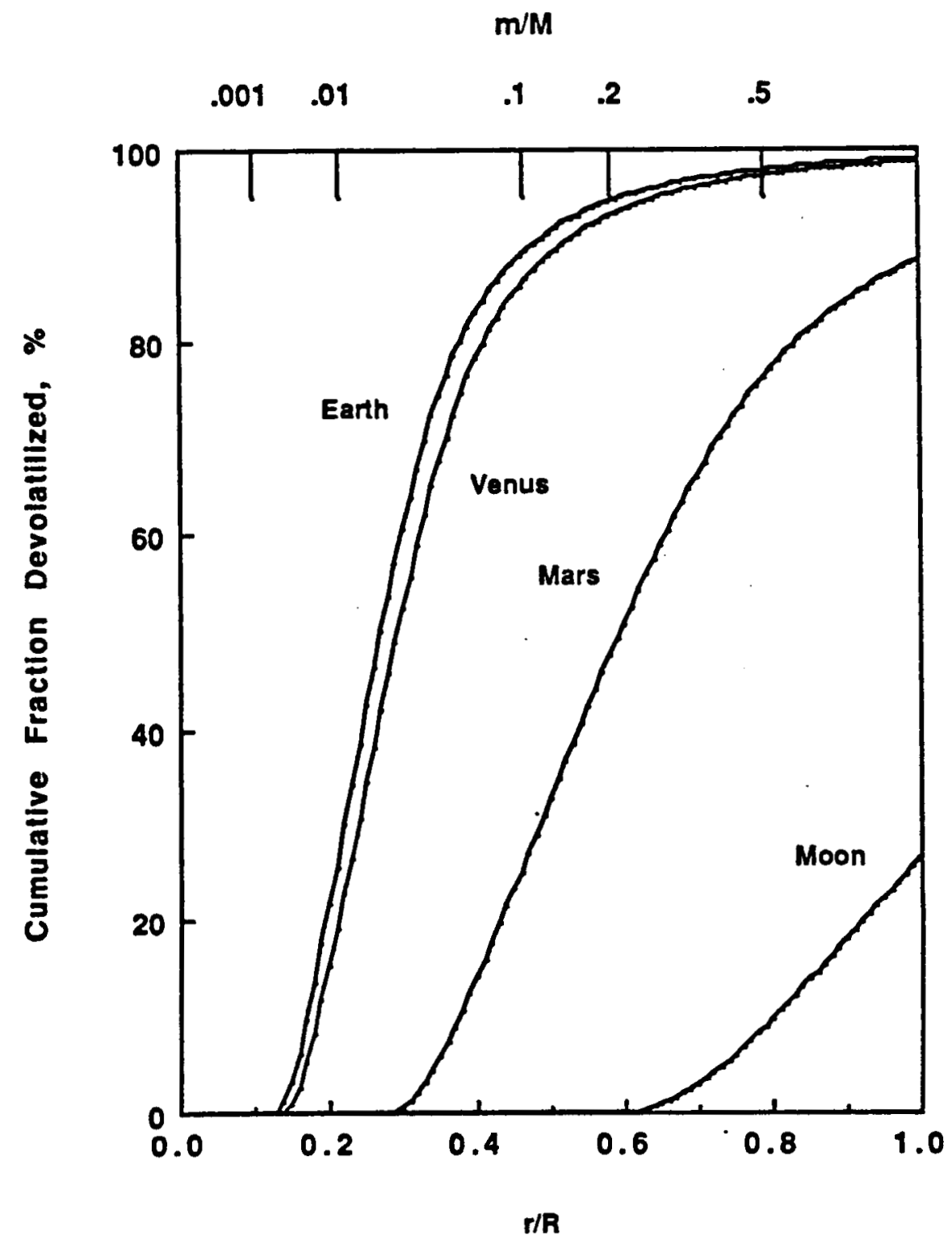

Figure 8 


\section{Impact-Induced D-H Fractionation}

During Accretion: Models

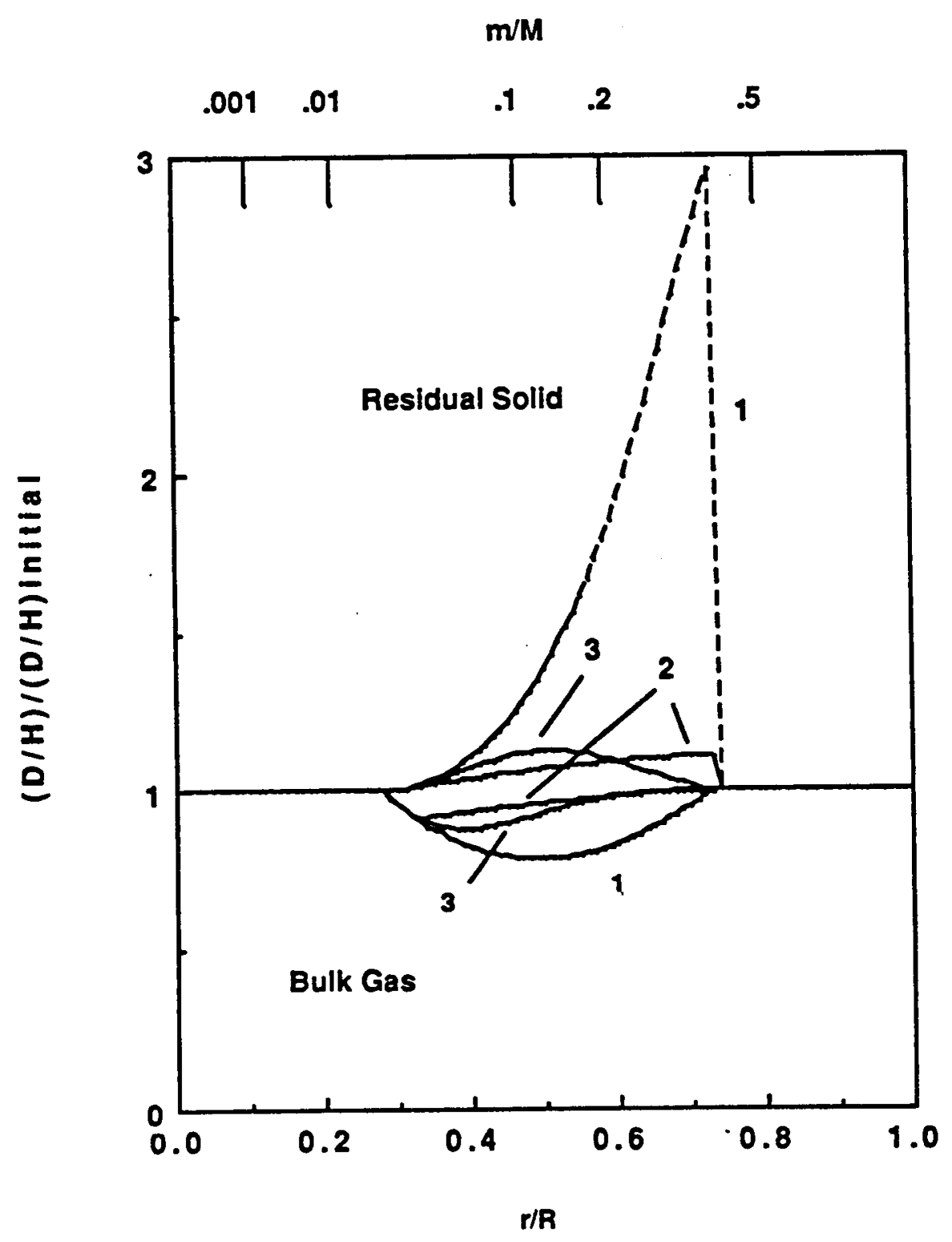

Figure 9 
Cumulative impact-Induced $\mathrm{D}-\mathrm{H}$

Fractionation During Accretion: Models

$\mathrm{m} / \mathrm{M}$

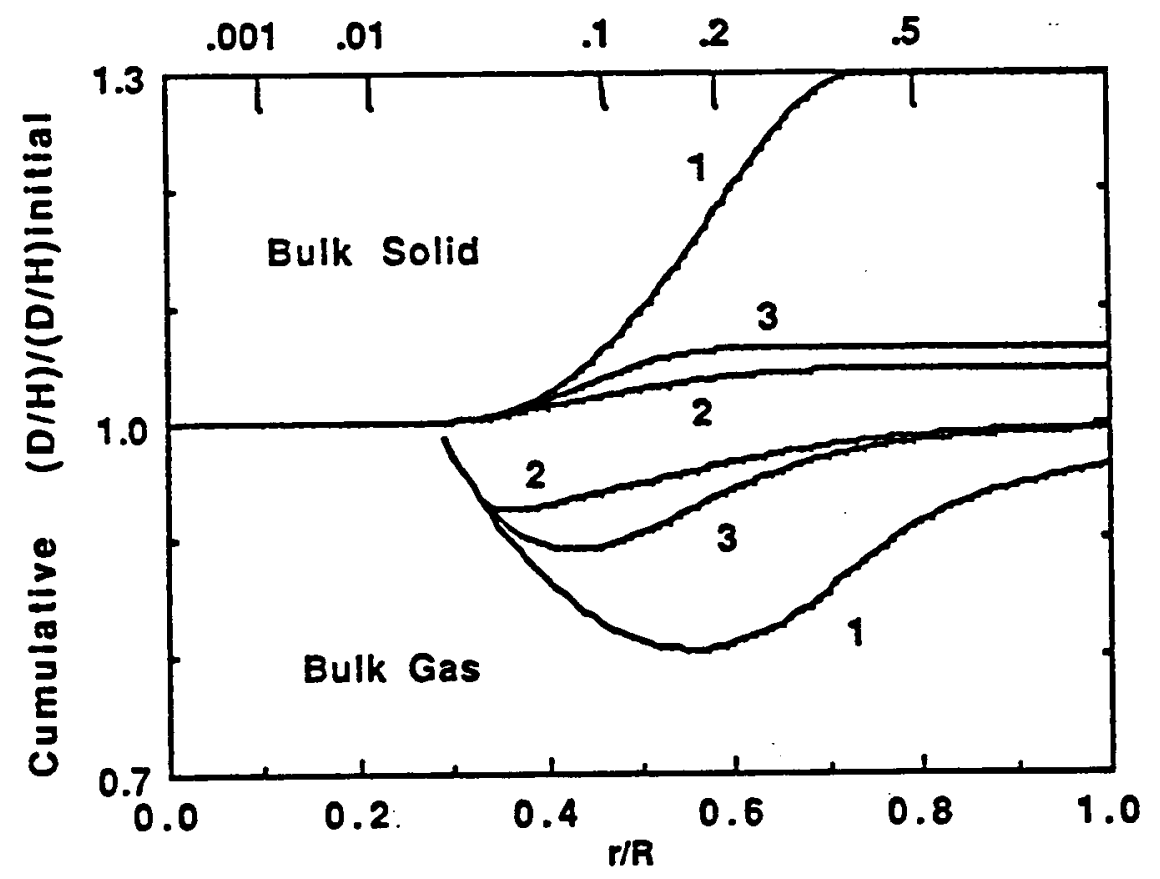

Figure 10

TJA88072SC 


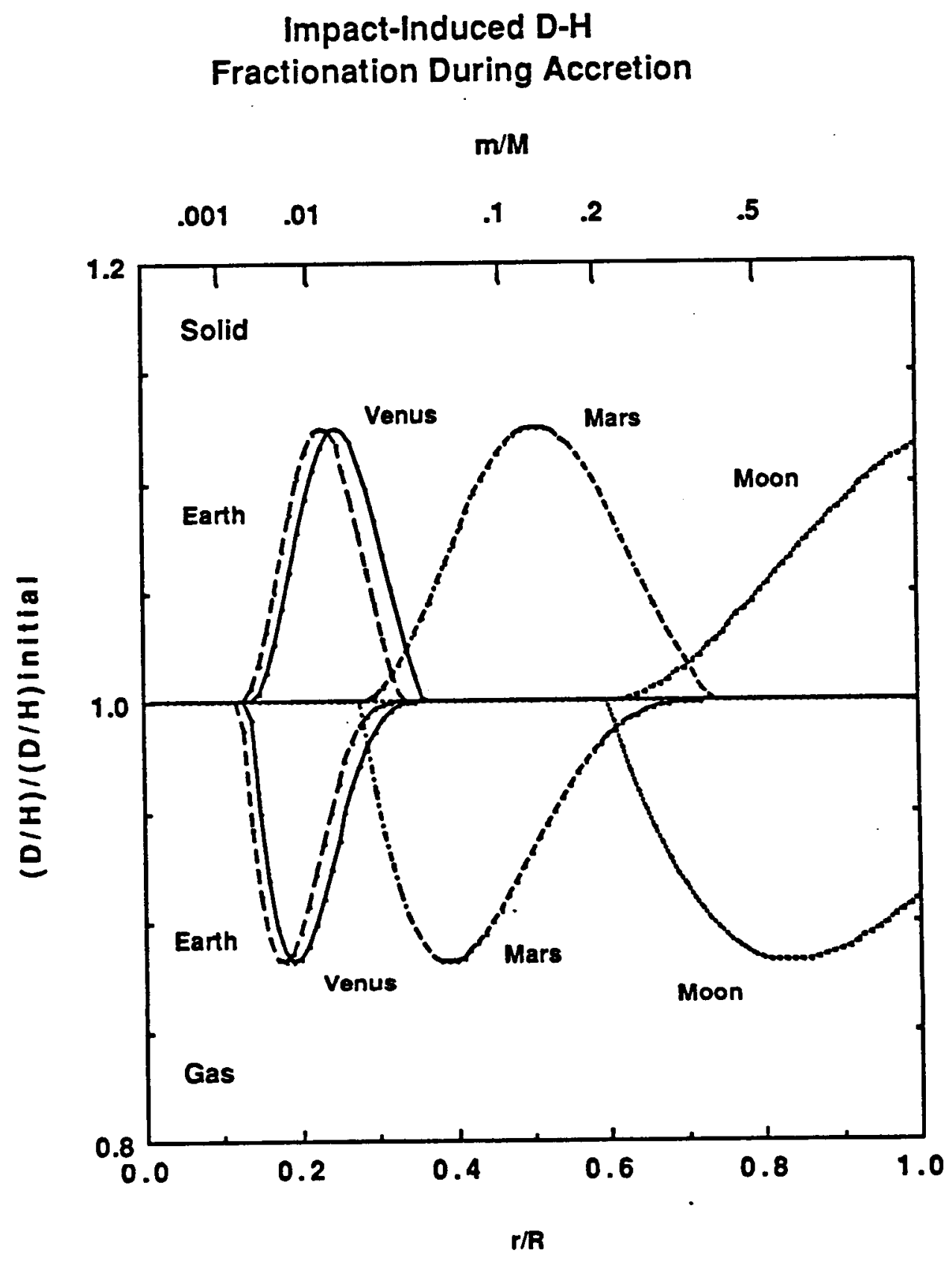

Figure 11 


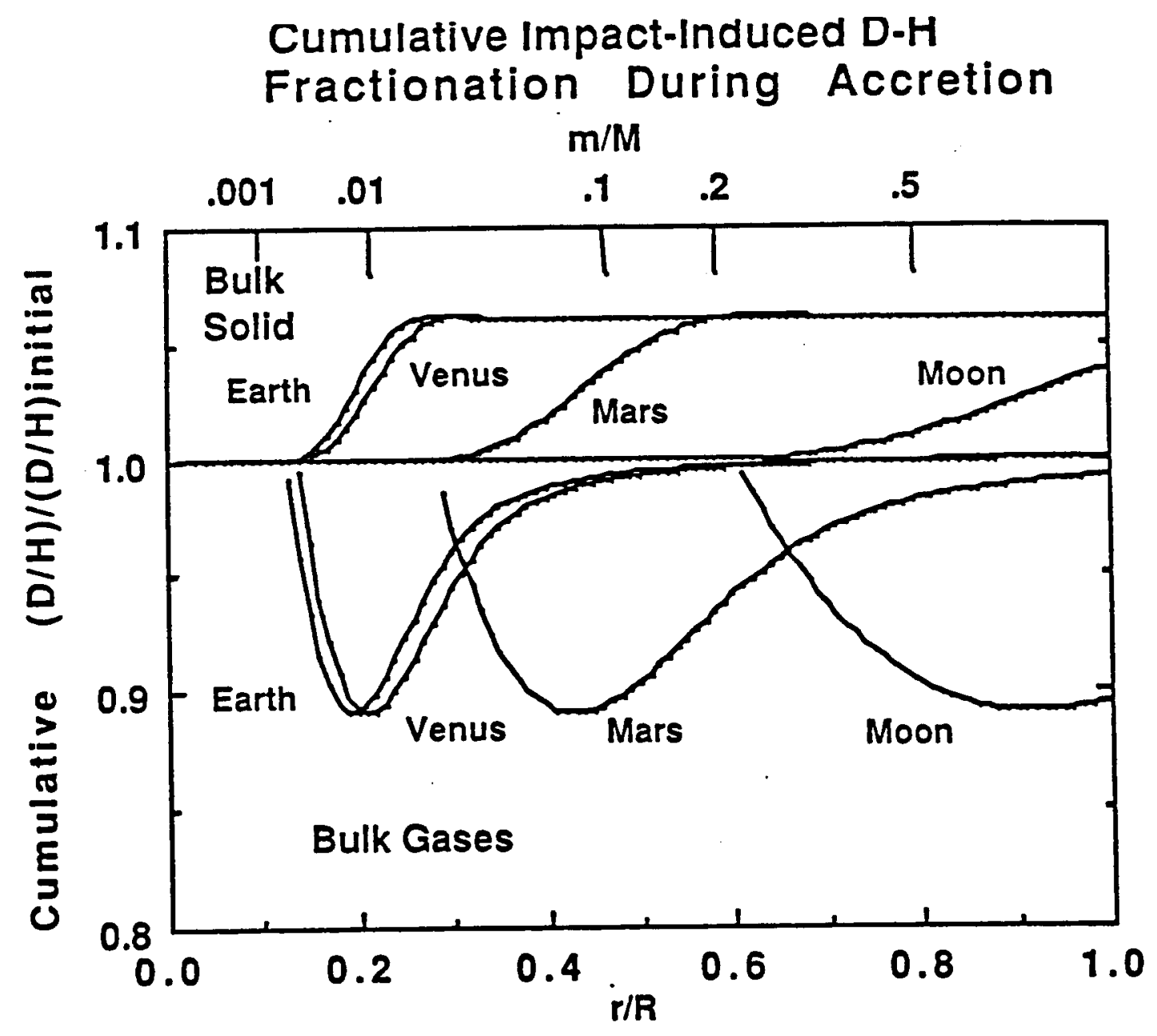

Figure 12 